\title{
ISOLATED LEFT VENTRICULAR NONCOMPACTION: UNUSUAL CAUSE OF DECOMPENSATED HEART FAILURE AND INDICATION OF HEART TRANSPLANTATION IN THE EARLY INFANCY - CASE REPORT AND LITERATURE REVIEW
}

Natasha Damásio Fairbanks Barbosa, Estela Azeka, Vera Demarchi Aiello, Fernanda Viana, Marcelo Jatene, Carla Tanamati, Miguel Barbero Macial

\section{INTRODUCTION}

The isolated noncompaction of the left ventricle (IVNC) is a rare disease, of which only about 100 cases have been reported so far. ${ }^{1}$ The World Health Organization has categorized it as an unclassified cardiomyopathy. It is supposedly the result of an arrest in the normal endomyocardial embryogenesis, which leads to the persistence of intertrabecular recesses and the development of a spongy myocardium. ${ }^{2}$ During normal intrauterine development, the myocardium condenses and the intertrabecular recesses are reduced to capillaries ${ }^{1}$. IVNC is characterized by an excessively prominent trabecular meshwork of the myocardium and deep intertrabecular recesses due to the arrest in the compactation process of the myocardial fibers in the absence of other structural heart disease, ${ }^{3,4}$ Jenni et al ${ }^{5}$ defined the diagnostic echocardiographic criteria for IVNC and suggested that the World Health Organization classification of cardiomyopathies should consider including it as a distinct cardiomiopathy. Recently, it was recognized as a congenital cardiomyopathy. ${ }^{6}$ Due to the rarity of the disease and to the difficulty of diagnosis, we are reporting an infant with isolated left ventricular noncompaction who presented decompensated heart failure and was successfully submitted to heart transplantation.

\section{CASE DESCRIPTION}

A female infant, aged 10 months, arrived at our hospital and was admitted with clinical signs of heart failure and a history of a previous admission at Intensive Care Unit for decompensated heart failure and cardiac arrest one

Cardiology Unit, Heart Institute, Faculdade de Medicina da Universidade de São Paulo - São Paulo/SP, Brazil.

natashadamasio@gmail.com month before. She was born at term of healthy, unrelated parents and was asymptomatic until the age of two months, when she presented with shortness of breath, poor appetite and weight loss. She weighed $6.8 \mathrm{Kg}$ and was $75.5 \mathrm{~cm}$ tall. Cardiovascular examination revealed a decreased-volume peripheral pulse and a third heart sound. There was also hepatomegaly, $4 \mathrm{~cm}$ below the right costal margin. No dysmorphic features were observed. There was no sign of arrhythmia noted while awaiting transplantation.

The patient evolved with refractory heart failure as a result of severely deteriorated left ventricular function and became a candidate for heart transplantation. On admission, the infant's medications were aldactone $1.5 \mathrm{mg} / \mathrm{kg} /$ day, captopril $1.5 \mathrm{mg} / \mathrm{kg} /$ day, furosemide $3.5 \mathrm{mg} / \mathrm{kg} / \mathrm{day}$ and digoxin $10 \mathrm{mg} / \mathrm{kg} /$ day.

During the pre-transplantation exams, the chest X-ray revealed substantial cardiomegaly. The electrocardiography showed left ventricular overload, but no signs of ventricular arrhythmias. The echocardiogram showed dilated cardiac chambers (important enlargement of left atrium and left ventricle). There was a severe left ventricular systolic dysfunction (shortening fraction of $7.3 \%$ ) and a discrete left atrioventricular valve insufficiency, with no signs of thrombosis. The dimension of the septum and left ventricular wall was $6 \mathrm{~mm}$ thick. Gallium-67 scintigraphy for myocardial inflammatory process was negative. An endomyocardial biopsy revealed no evidence of myocarditis. Cardiac catheterization showed a systolic pulmonary pressure of 28 $\mathrm{mmHg}$, diastolic pulmonary pressure of $18 \mathrm{mmHg}$, mean pulmonary pressure of $21 \mathrm{mmHg}$, capillary wedge pressure of $15 \mathrm{mmHg}$, pulmonary vascular resistance index of 1.8 Woods $/ \mathrm{m}^{2}$.

The patient underwent heart transplantation at the age of 1 year, 37 days after having been listed. The donor heart was from a 5-year-old boy who weighed $15 \mathrm{Kg}$ and had suffered an acute head trauma. During the immediate pos- 
operative period, the patient evolved with right ventricle dysfunction but her condition improved after nitric oxide inhalation. On the second day after surgery, she was extubated and on the sixth day, the vasoative drugs were discontinuated. Sixteen days after surgery, she was discharged in good clinical conditions, and is now doing well, two years and 10 months after transplantation.

The pathology analysis of the explanted heart revealed ventricles with proeminent ventricular trabeculation and deep recesses, involving the inlet and the apical portion. The compact myocardium was thin $(3 \mathrm{~mm})$ and endocardium showed diffuse thickening. The ratio of thickness of noncompacted-to-compacted myocardium was 3.3. The septum was $8 \mathrm{~mm}$ thick and there was myocardial hypertrophy, consistent with the diagnosis of dilated cardiomyopathy with isolated noncompaction of the left ventricular myocardium or "spongy myocardium" (Figure 1). Microscopically, the deep recesses were lined by a thickened endocardial layer and the myocardial fibers showed mild hypertrophy (Figure 2). No inflammatory infiltrate was detected.

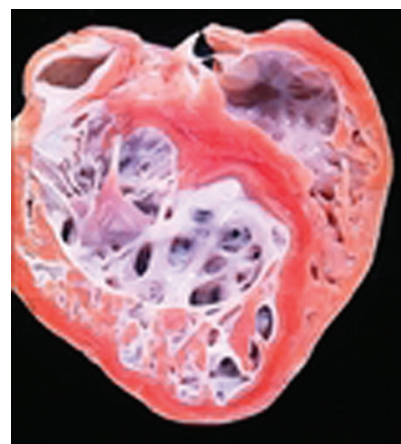

Figure 1 - Gross aspect of the explanted heart, showing the characteristic non-compaction involving the inlet and apical portion of the left ventricle but sparing the ventricular septum.
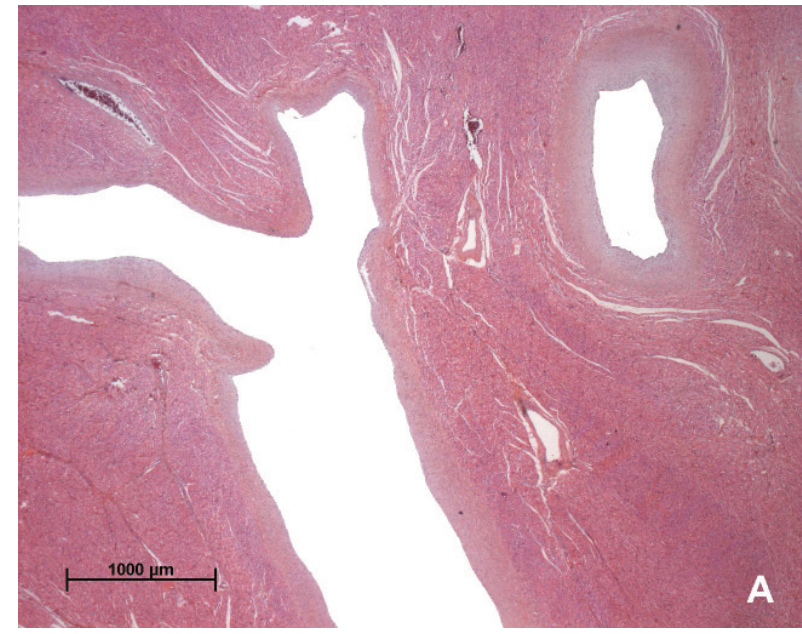

\section{DISCUSSION}

During normal embryonic development, endomyocardial trabeculations emerge from the apical region of the primitive ventricles at day 32 of fetal life, and involute by day 70 through a process of reabsortion and remodeling. ${ }^{7}$ Noncompaction is characterized by numerous, prominent trabeculations and conspicuous intertrabecular recesses that penetrate deeply into the left ventricular myocardium, a thin compacted ventricular free wall, mainly in the affected areas, and hypokinetic diffuse systolic dysfunction. ${ }^{3}$ It should be distinguished from persistent intramyocardial sinusoids, commonly seen in hearts with structural abnormality and intraventricular pressure overload such as with pulmonary atresia and intact ventricular septum. These intramyocardial sinusoids are in continuity with the ventricular cavity and with the coronary arteries. ${ }^{8}$

The thickened left ventricular wall consists of two zones of different structure. The compacted epicardial layer appears as a compact band of uniform tissue while the much thicker endocardial non-compacted layer consists of trabecular meshwork with deep endomyocardial spaces surrounded by exaggerated hypertrophy of the trabeculae. Although it must be emphasized that, strictly speaking, a two layered structure is found only in IVNC, and not in left ventricular hypertrophy (LVH), dilated cardiomyopathy (DCM), or any other condition, it may sometimes appear difficult to define where prominent trabeculation (such as DCM) ends and non-compactation begins. ${ }^{5}$

The microscopical findings are non-specific and may comprise hypertrophy of cardiomyocytes and endocardial fibroelastosis.

Clinical symptoms depend on the extent of noncompacted cardiac segments ${ }^{3}$. Most children with IVNC

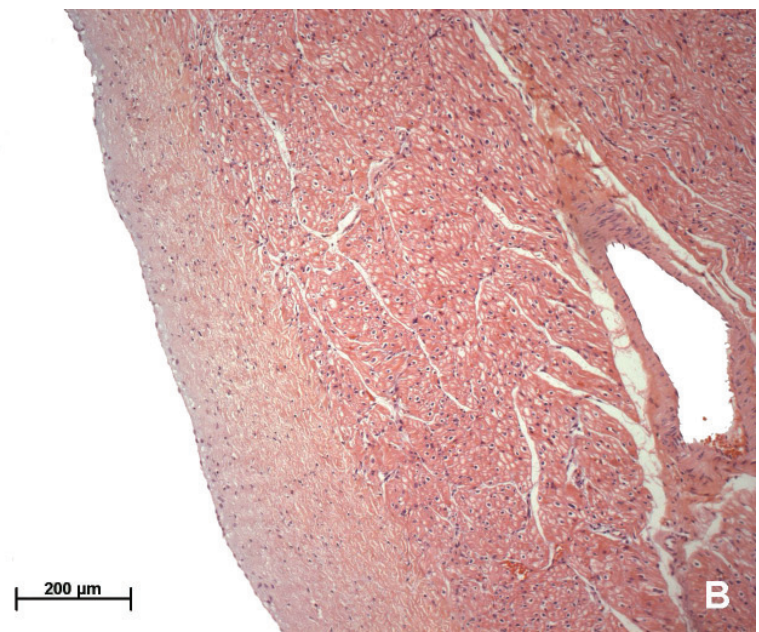

Figure 2 - Photomicrographs of the left ventricular myocardium showing in A) the deep myocardial recesses and in B) the thickened endocardium. Hematoxylin-eosin satin, objectives A) $2.5 \mathrm{X}$ and B) $10 \mathrm{X}$. 
are asymptomatic on initial presentation and show gradual deterioration in left ventricular function with restrictive physiology. ${ }^{3}$ In reports of predominantly symptomatic children, heart failure and arrhythmia were prevalent. ${ }^{9-11}$ There also seems to be an increased incidence of ventricular arrhythmias in adults. ${ }^{12,13}$ Systemic embolization is another major cause of severe, often fatal complication. In an adult population with IVNC, Oeschslin et $\mathrm{al}^{13}$ reported four cases that required heart transplantation for end-stage cardiac failure. Ichida et $\mathrm{al}^{3}$ reported 27 pediatric patients with IVNC but only 3 patients experienced progressive left ventricular dysfunction during a median follow-up of 6 years. Two of these patients died and the other was a candidate for heart transplantation. Neudorf et $\mathrm{al}^{10}$ reported 7 cases of IVNC in children, but in only one transplantation was performed and $\mathrm{Chin}_{\text {et }} \mathrm{al}^{9}$ reported 8 patients in a single institution, but none was candidate to heart transplantation. Wald et $\mathrm{al}^{11}$ described 3 of 22 patients who became candidates for heart transplantation. To our knowledge, our case is the youngest infant with a clinical presentation of decompensated heart failure to be successfully treated with heart transplantation.

The cause of depressed ventricular function is not clear, but it seems to be the result of a primary systolic and diastolic dysfunction of the left ventricle. Systolic dysfunction is most probably the result of relative ischemia of the myocardium due to the mismatch of myocardial oxygen supply and demand. ${ }^{14}$ The coronary arteries are normal in the affected patients. Recently, however restricted myocardial perfusion and decreased coronary flow reserve, suggestive of a coronary microcirculatory dysfunction, were demonstrated through positron emission tomography in patients with IVNC..$^{15,16}$ Decreased coronary flow reserve was not only confined to noncompacted segments, but extended to most segments with wall motion abnormalities. ${ }^{16}$ This finding suggests that coronary microcirculatory dysfunction may play a role in the development of impaired ventricular function. Patients with depressed ventricular function may present signs of heart failure similar to those observed in patients with dilated cardiomyopathy, and which were seen in this infant.

IVNC can occur in sporadic and in familial patterns. Familial cases have been reported, where the mode of inheritance is heterogeneous. In the X-linked form of the disease, a locus has been found on Xq28, and mutations have been reported in G4.5 gene. ${ }^{17,18}$ This genetic linkage is located close to other areas that have been associated with various other myopathies. In our case, a family history was excluded.

The morphological criteria for the diagnosis of this entity remain the subject of debate and are usually based on the findings of the imaging studies. Echocardiography is the diagnostic tool for IVNC, however different echocardiographic criteria for IVNC are currently been used ${ }^{19}$ : echocardiografic data that would help differentiate IVNC from idiopathic dilated cardiomyopathy (IDC) have not been fully described. The depths of the recesses may be difficult to assess echocardiographically and might be dependent on the patient's hemodynamic status ${ }^{19}$. Jenni et $\mathrm{al}^{5}$ have described diagnostic echocardiographic criteria for IVNC that include 1) the absence of co-existing cardiac abnormalities; 2) a 2-layered structure of the ventricular wall with an end-systolic ratio of the noncompacted to the compacted layer $>2$; 3) the finding of this morphologic presentation in apical and in mid-ventricular areas, and 4) direct blood flow from the ventricular cavity into the deep intertrabecular recesses, as assessed by Doppler echocardiography. Magnetic resonance imaging and myocardial perfusion scanning can be of additional help in detecting sub-endocardial perfusion defects. ${ }^{20,21} \mathrm{~A}$ recent resonance magnetic study concluded that a ratio of non-compacted to compacted myocardium greater than 2.3 would reliably the disease entity ${ }^{22}$. Ivan et $a^{23}$ reported three cases where the diagnosis of ventricular non-compactation was not made by echocardiography, but by cardiac magnetic resonance. They suggest that the regular use of cardiac magnetic resonance may improve the detection rate of IVNC in patients with IDC.

It should be however noted that in the case reported here, echocardiography only showed a dilated left ventricle compatible with dilated cardiomyopathy and a severe left ventricle dysfunction. The diagnosis of isolated noncompaction was only established on the explanted heart. The microscopical findings are non-specific and may comprise hypertrophy of cardiomyocytes and endocardial fibroelastosis. This finding demonstrates that the diagnosis of IVNC may be difficult before transplantation. Sengupta et $\mathrm{al}^{24}$ reported that in symptomatic patients, the differentiation of IVNC from other cardiomyopathies may be difficult. Several cases of IDC have been shown to be IVNC at authopsy ${ }^{25}$.

Patients with noncompactation of the left myocardium reveal a poor outcome, the mortality, exceeding $35 \%$ in adults, ${ }^{12}$ and in children, the mortality rate exceeded $22 \%$ in a 7-year follow-up study ${ }^{26}$. The commonest causes of death are intractable heart failure and sudden cardiac death. ${ }^{13}$

The management of patients with IVNC includes the treatment of congestive heart failure, arrhythmias, and thromboembolic events. End-stage heart failure has been managed with heart transplantation, as evidenced in our case. A review of the literature identified only 9 patients 
with IVNC who underwent cardiac transplantation. ${ }^{8,27}$ This infant is the youngest child reported with IVNC and clinical signs of decompensated heart failure to have been successfully treated with heart transplantation.

\section{CONCLUSION}

Although a rare entity, isolated ventricular noncompactation can lead to decompensated heart failure in the early infancy and may be successfully treated with heart transplantation.

\section{REFERENCES}

1. Khan IA, Biddle WP, Najeed SA, Abdul-Aziz S, Mehta NJ, Salaria V, et al. Isolated noncompaction cardiomyopathy presenting with paroxysmal supraventricular tachycardia-case report and literature review. Angiology. 2003;54:243-50.

2. Hook S, Ratliff NB, Rosenkranz E, Sterba R. Isolated noncompaction of the ventricular myocardium. Pediatr Cardiol. 1996;17:43-5.

3. Ichida F, Hamamichi Y, Miyawaki T, Ono Y, Kamiya T, Akagi T, et al. Clinical features of isolated noncompaction of the ventricular myocardium: long-term clinical course, hemodynamic properties, and genetic background. J Am Coll Cardiol. 1999;34:233-40.

4. Chenard J, Samson M, Beaulieu M. Embryonal sinusoids in the myocardium: report of a case successfully treated surgically. Can Med Assoc J. 1965;92;1356-9.

5. Jenni R, Oechslin E, Schneider J, Attenhofer Jost C, Kaufmann PA. Echocardiographic and pathoanatomical characteristics of isolated left ventricular non-compaction: a step towards classification as a distinct cardiomyopathy. Heart. 2001;86:666-71.

6. Maron BJ, Towbin JA, Thiene G, Antzelevitch C, Corrado D, Arnett D, et al. Contemporary definitions and classification of the cardiomyopathies: An American Heart Association Scientific Statement from the council on clinical cardiology, heart failure and transplantation committee; quality of care and outcomes research and functional genomics and translational biology interdisciplinary working groups; and council on epidemiology and prevention. Circulation. 2006;113;1807-16.

7. Collins P. Embryology: development of the heart. In: Willians PL, ed Gray's Anatomy, 38 ${ }^{\text {th }}$ editor. London: Churchill Livingstone;1995. p. 182.

8. Vogel M, Chaudhari M, Rassi D, Mair L, Hasan A. End-Stage Cardiac Failure Caused by Isolated Ventricular Non-Compactation: Cardiac Transplantation in a 5-Year-Old Boy. J Heart Lung Transplant. $2005 ; 24 ; 618-20$.

9. Chin TK, Perloff JK, Williams RG, Jue K, Mohrmann R. Isolated noncompaction of left ventricular myocardium. A study of eight cases. Circulation. 1990;82;507-13.

10. Neudorf UE, Hussein A, TRowitzsch E, Schmaltz AA. Clinical features of isolated noncompactation of the myocardium in children. Cardiol Young. 2001;11;439-442.

11. Wald R, Veldtman G, Golding F, Kirsh J, McCrindle B, Benson L. Determinants of Outcome in Isolated Ventricular Noncompactation in Childhood. Am J Cardiol. 2004;94;1581-1584.

12. Duru F, Candinas R. Noncompaction of ventricular myocardium and arrhythmias. J Cardiovasc Electrophysiol. 2000;11;493.

13. Oechslin EN, Attenhofer Jost CH, Rojas JR, Kaufmann PA, Jenni R. Long-term follow-up of 34 adults with isolated left ventricular noncompaction: a distinct cardiomyopathy with poor prognosis. J Am Coll Cardiol. 2000;36;493-500.
14. Agmon Y, Connolly HM, Olson LJ, Khandheria BK, Seward JB. Noncompaction of the ventricular myocardium. J Am Soc Echocardiogr. $1999 ; 12 ; 859-63$.

15. Junga G, Kneifel S, Von Smekal A, Steinert H, Bauersfeld U. Myocardial ischaemia in children with isolated ventricular non-compaction. Eur Heart J. 1999;20:910-6.

16. Jenni R, Wyss CA, Oechslin EN, Kaufmann PA. Isolated ventricular noncompaction is associated with coronary microcirculatory dysfunction. J Am Coll Cardiol. 2002;39;450-4.

17. Ichida F, Tsubata S, Bowles KR, Haneda N, Uese K, Miyawaki T, et al Novel gene mutations in patients with left ventricular noncompaction or Barth syndrome. Circulation. 2001;103;1256-1263.

18. Bleyl SB, Mumford BR, Brown-Harrison MC, Pagotto LT, Carey JC, Pysher TJ, et al. Xq28-linked noncompaction of the left ventricular myocardium: Prenatal diagnosis and pathologic analysis of affected individuals. Am J Med Genet. 1997;72;257-265.

19. Stöllberger C, Finsterer J. Left ventricular hypertrabeculation/ noncompaction. J Am Soc Echocardiogr. 2004;17;91-100.

20. Conraads V, Paelinck B, Vorlat A, Goethals M, Jacobs W, Vrints C. Isolated non-compaction of the left ventricle: a rare indication for transplantation. J Heart Lung Transplant. 2001;20;904-7.

21. Buonanno C, Variola A, Dander B, Gabaldo S, Marafioti V. Isolated noncompaction of the myocardium. An exceedingly rare cardiomyopathy: A case report. Ital Heart J. 2000;1;301-5.

22. Petersen SE, Selvanayagam JB, Wiesmann F, Robson MD, Francis JM, Anderson RH, et al. Left ventricular non-compaction: insights from cardiovascular magnetic resonance imaging. J Am Coll Cardiol. 2005;46;101-5.

23. Ivan D, Flamm SD, Abrams J, Kindo M, Heck K, Frazier OH. Isolated Ventricular Non-Compactation in Adults with Idiopathic Cardiomyopathy: Cardiac Magnetic Resonance and Pathologic Characterization of the Anomaly. J Heart Lung Transplant. 2005;24;781786.

24. Sengupta PP, Mohan JC, Mehta V, Jain V, Arora R, Pandian NG, et al Comparison of echocardiographic features of noncompaction of the left ventricle in adults versus idiopathic dilated cardiomyopathy in adults. Am J Cardiol. 2004;94;389-91.

25. Varnava AM. Isolated left ventricular non-compaction: a distinct cardiomyopathy? Heart. 2001;86;599-600.

26. Alehan D. Clinical features of isolated left ventricular noncompaction in children. Int J Cardiol. 2004;97;233-7.

27. Stamou SC, Lefrak EA, Athari FC, Burton NA, Massimiano PS. Heart transplantation in a patient with isolated noncompaction of the left ventricular myocardium. Ann Thorac Surg. 2004;77;1806-8. 
Clinics vol.63 no.1 February/2008

Authors - Page 136

Replace: Miguel Barbero Macial

For: Miguel Barbero Marcial 
This article has received corrections in agreement with the ERRATUM published in Volume 63 Number 2. 